\title{
Speciation of Inorganic Arsenic by Electrothermal Vaporization-Inductively Coupled Plasma Mass Spectrometry After Solidified Floating Organic Drop Microextraction
}

\author{
Shizhong Chen •, Yuanyuan He, Shengping Zhu, and Dengbo Lu \\ College of Chemical and Environmental Engineering, Wuhan Polytechnic University, \\ 68 Xuefu South Road Changqing Garden, Wuhan 430023, P.R. China
}

\section{INTRODUCTION}

It is well known that arsenic (As) is a ubiquitous element in the environment due to its wide application. Arsenic is known to be one of the most toxic elements and has serious effects on plants, animals, and human health $(1,2)$. What is more, the toxicity, bioavailability, and reactivity of As is strongly dependent on its chemical forms (3-5). The inorganic species of As are more toxic than their organic forms (6). The toxicity of As(III) is 10-20 times higher than that of As(V) (7). In addition, its oxides have been shown to cause several types of cancer (8). In the majority of environmental samples, such as natural water and fly ash, As is usually present as As(V) and As(III) because these oxidation states are the most environmentally mobile and geochemically important forms of these elements (9). Hence, a simple, fast, sensitive, reproducible, and accurate analytical method for the speciation of inorganic As in natural water is required for evaluating their possible effect on fauna, flora, and human health.

In general, elemental speciation can be carried out by combining a sensitive detection technique with an effective separation method. Although the combination of chromatography with a specific element detector is a powerful tool for speciation, non-chromatographic methodology is still an attractive alternative because it can offer a

\footnotetext{
*Corresponding author.

E-mail: chenshizbong62@163.com

Fax: +862783956442
}

\section{ABSTRACT}

Based on solidified floating organic drop microextraction (SFODME), a novel method was developed for speciation of inorganic arsenic (As(V)/As(III)) by electrothermal vaporization inductively coupled plasma mass spectrometry (ETV-ICP-MS). Ammonium pyrroinedithiocarbamate (APDC) was used as both a chelating reagent in SFODME and a chemical modifier in ETV. As(III) could react with APDC to form complexes at $\mathrm{pH} \mathrm{5.5, \text {and }}$ the complexes were quantitatively extracted into an organic phase of 1-dodecanol, whereas As(V) remained as a free species in the aqueous phase. As(III) was directly determined by ETV-ICPMS. Total As was determined by the same method after reducing As(V) to As(III). The assay of As(V) was obtained by subtracting As(III) from total As. The main factors affecting the separation and determination, including $\mathrm{pH}$, amount of APDC, extraction time, stirring rate, sample solution volume, and temperature program, were examined in detail. Under optimized conditions, the detection limits were $0.36 \mathrm{pg} \mathrm{mL}^{-1}$ for As(III) and $0.91 \mathrm{pg} \mathrm{mL}^{-1}$ for As(V). The relative standard deviations for As(III) and As(V) were $5.1 \%$ and $5.7 \%\left(\mathrm{c}=1.0 \mathrm{ng} \mathrm{mL}^{-1}\right.$, $\mathrm{n}=9$ ), respectively. This method was applied for the speciation of inorganic arsenic in natural water samples and standard reference materials with satisfactory results. simple and inexpensive way for the discrimination of specific or toxic forms of an element (10). Many non-chromatographic techniques, such as coprecipitation, solvent extraction, cloud point extraction, solid phase extraction, ion exchange, hydride generation, and liquid phase microextraction (LPME), have been used for elemental speciation (11-18). It is worth noting that recently a new LPME technique, namely solidified floating organic drop microextraction (SFODME), has been drawing considerable attention in analytical chemistry. Owing to its unique merits of simplicity, speed, low cost, limited consumption of organic solvent, and high enrichment factor, SFODME has been used widely for the determination of trace elements (19).

Up to date, atomic absorption spectrometry (AAS), inductively coupled plasma atomic emission spectrometry (ICP-AES), and inductively coupled plasma mass spectrometry (ICP-MS) still represent the most important routine techniques for elemental analysis. However, AAS suffers from limited matrix tolerance and single-element detection ability in real sample analysis. ICP-AES allows fast and multielement analysis, but it often suffers from line-rich spectral interferences of some elements. Relatively, ICP-MS is the most favorable choice for elemental analysis owing to its high sensitivity, wide linear range, rapid multielement detection capability. and lack of line-rich spectral interferences encountered in ICP-AES. It is predicted that SFODME coupled with ICP-MS may 
be a powerful detection tool for elements. Unfortunately, the liquid nebulization sample introduction procedure for conventional ICP-MS is not compatible with SFODME because of its large sample consumption. In addition, organic solvents used in SFODME may lead to destabilization or extinction of ICP discharge owing to the relatively high solvent vapor pressure and solvent loading (20). Thus, the development of a suitable sample introduction technique with a small amount of sample consumption and in situ removal of the organic solvent is a promising and prospective work for extending the application of the SFODME technique.

Electrothermal vaporization (ETV), as a sample introduction device for ICP-MS, has the merits of high introduction efficiency, small sample requirement, and low absolute detection limit. Moreover, use of a chemical modifier in ETV could greatly improve the analytical performance of the method (21). As described previously, SFODME is a miniaturized sample pretreatment technique, and ETV is a micro-amount sample introduction device. Therefore, SFODME coupled with ETV for ICP-MS may be a perfect combination. Much work has been done using SFODME coupled with AAS for separation and preconcentration of trace elements (22-27), but only a few researchers reported using ICP-MS (28-30). It is especially worth noting that the study on SFODME-ETV-ICP-MS for elemental speciation has received little attention so far.

In the present work, an attempt has been made to develop SFODME coupled with ETV-ICP-MS for the speciation of inorganic arsenic. Ammonium pyrroinedithiocarbamate (APDC) was used as both a chelating reagent in SFODME and as a chemical modifier in ETV for separation, preconcentration, and volatilization of the analytes As(III) and As(V) prior to their determination by ICP-MS. The main factors affecting the determination of the analytes were investigated in detail. The feasibility of this method was assessed by its application for speciation of inorganic As in natural water samples and standard reference materials.

\section{EXPERIMENTAL}

\section{Instrumentation}

An X-7 ICP-MS system (Thermo Elemental Corporation, USA), equipped with a modified commercially available WF-4C graphite furnace (Beijing Second Optics, P.R. China) as an electrothermal vaporizer, was used for the determination of the analytes. The operating parameters of the ICP-MS were optimized with a concentric glass nebulizer prior to connection with the ETV device. A pyrolytic graphite tube was used throughout this work. The working conditions of
ETV-ICP-MS are summarized in Table I. The $\mathrm{pH}$ value of the solution was monitored with a $\mathrm{pH}$ meter (Thermo Orion Corporation, USA) supplied with a combined electrode.

\section{Standard Solutions and Reagents}

Unless otherwise stated, all reagents used in this study were of the highest purity available or at least of analytical grade. High purity deionized water obtained from a Milli-Q ${ }^{\circledR}$ A10 system (Millipore Corporation, USA) was used throughout this work.

Stock standard solutions $(1.0 \mathrm{mg}$ $\mathrm{mL}^{-1}$ ) of As(III) and As(V) were obtained by dissolving appropriate amounts of $\mathrm{Na}_{3} \mathrm{AsO}_{3}$ and $\mathrm{Na}_{3} \mathrm{AsO}_{4}$ (Tianjin Reagent Factory, P.R. China) in high purity deionized water. Working solutions were prepared daily by appropriate dilution of the stock solutions. The APDC

TABLE I

Operating Parameters for ETV-ICP-MS

\begin{tabular}{ll}
\hline ICP-MS Plasma & \\
\hline Plasma Power & $1300 \mathrm{~W}$ \\
Plasma Argon Flow Rate & $14.5 \mathrm{~L} \mathrm{~min}^{-1}$ \\
Auxiliary Argon Flow Rate & $0.85 \mathrm{~L} \mathrm{~min}^{-1}$ \\
Nebulizer Argon Flow Rate & $0.92 \mathrm{~L} \mathrm{~min}^{-1}$ \\
Sampler Orifice (nickel) & $1.1 \mathrm{~mm}$ \\
Skimmer Orifice (nickel) & $0.7 \mathrm{~mm}$ \\
Acquisition Mode & Peak-jumping \\
Number of Sweep & 100 \\
Dwell Time & $10 \mathrm{~ms}$ \\
Acquisition Time & $40 \mathrm{~s}$ \\
Number of Measurements per Peak & 3 \\
Isotopes & $75 \mathrm{As}$ \\
\hline ETV & \\
\hline Sample Volume & $10 \mu \mathrm{L}$ \\
Carrier Gas Flow Rate & $0.45 \mathrm{~L} \mathrm{~min}{ }^{-1}$ \\
Drying Step & $100{ }^{\circ} \mathrm{C}$, ramp $10 \mathrm{~s}$, hold $10 \mathrm{~s}$ \\
Ashing Step & $200{ }^{\circ} \mathrm{C}$, ramp $10 \mathrm{~s}$, hold $30 \mathrm{~s}$ \\
Vaporization Step & $2000^{\circ} \mathrm{C}$, hold $4 \mathrm{~s}$ \\
Clear-out Temperature & $2600^{\circ} \mathrm{C}$ \\
\hline
\end{tabular}


solution was prepared by dissolving the proper amount of APDC (Shanghai Reagent Factory, P.R. China) in 1-undecanol (Shanghai Reagent Factory, P.R. China). All glass and polypropylene wares were kept in $2.0 \mathrm{~mol} \mathrm{~L}^{-1} \mathrm{HNO}_{3}$ solution for at least one night, then rinsed with $0.1 \mathrm{~mol} \mathrm{~L}^{-1} \mathrm{HNO}_{3}$ solution, and subsequently with twice-distilled water before use.

\section{Sample Preparation}

Water samples, including river water (Yangtze River, Wuhan, P.R. China) and lake water (Dongxi Lake, Wuhan, P.R. China), were collected in 50-mL polyethylene containers. All water samples were filtered through a $0.45-\mu \mathrm{m}$ membrane filter and then stored in polyethylene bottles at $4{ }^{\circ} \mathrm{C}$ for future use. The storage period was kept as short as possible. The blanks were prepared exactly as the samples except that no analytes were added.

\section{SFODME Extraction}

In this work, the SFODME device for extraction of the analytes was similar to that described in the literature (31). The sample solution containing the analytes was adjusted to $\mathrm{pH} 5.5$ using diluted nitric acid or ammonium hydroxide. Then $10 \mathrm{~mL}$ of the resulting solution was transferred into an 11-mL vial, and a stir bar and $20 \mu \mathrm{L}$ of APDC in 1-dodecanol was added. The magnetic stirrer was turned on, and the solution stirred for a fixed time. In this step, the analytes reacted with APDC to form hydrophobic complexes and were extracted into 1-undecanol. After the extraction process was completed, the sample vial was transferred into an ice bath until the organic solvent solidified. The solidified solvent was then transferred into a conical vial where it melted immediately at room temperature. The extract was diluted to $100 \mu \mathrm{L}$ with tetrahydrofuran (THF). Finally, $10 \mu \mathrm{L}$ of the extract was injected into the ETV for ICP-MS determination.

\section{ETV-ICP-MS Procedure}

After the ETV unit had been connected to the ICP-MS, $10 \mu \mathrm{L}$ of the analytes in the organic solvent was injected into the graphite furnace. During the drying and charring process, the dosing hole of the graphite furnace was kept open to remove the water and the organic vapor. Then it was sealed with a graphite probe within 5-10 seconds prior to the vaporization step, the vaporized analytes were swept into the plasma excitation source by a carrier gas, and the peak-hop transient mode for data acquisition was used for the detection of the analytes.

\section{Data Analysis}

As(III) was directly determined by this method. Total As was determined after the reduction of As(V) to As(III), and the concentration of As(V) was calculated by the respective difference between the total As and As(III) concentration. Prereduction of As(V) to As(III) was carried out with $0.5 \%$ (w/v) L-cysteine media for 30 minutes in a boiling water bath (32).

\section{RESULTS AND DISCUSSION}

\section{Signal Profiles of As(III)}

Figure 1 shows the typical signal profiles of As(III) with and without the addition of APDC as a chemical modifier. It can be seen from Figure 1 that in the absence of APDC, As(III) (b) was partly vaporized at $2000{ }^{\circ} \mathrm{C}$ and its severe memory signal was recorded (c). In the presence of APDC, however, the intensive signal of As(III) (d) was detected at the same vaporization temperature, and no memory signal was observed for As(III) even at $2600{ }^{\circ} \mathrm{C}$ (e). In addition, the blank signal was not found in this experiment (a). The possible reason for this is that As(III) can form thermally stable and volatile As(III)-APDC complexes. Thus, APDC was selected as the suitable chemical modifier for ETV-ICP-MS.

\section{Effect of pH on SFODME}

It is well known that the $\mathrm{pH}$ of the sample solution plays an essential role in the complex formation and subsequent extraction. Thus, the effects of $\mathrm{pH}$ on the signal intensity of As(III) and As(V) were investigated in the $\mathrm{pH}$ range of

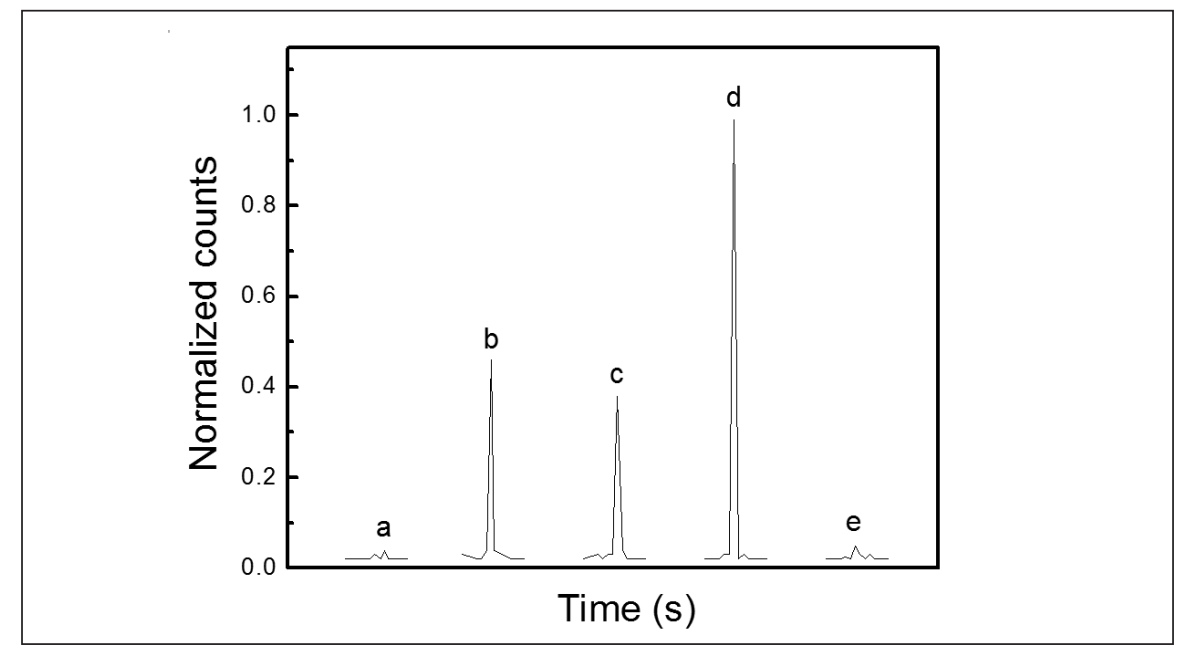

Fig. 1. Signal profiles of As(III). (a): APDC in 1-undecanol and THF; (b): As(III) aqueous solution; (c): residual signal from $b$ at $2600^{\circ} \mathrm{C} ;($ d): As(III) with APDC in 1-undecanol and THF; (e): residual signal from (d) at $2600^{\circ} \mathrm{C}$. As (III): $5.0 \mathrm{ng} \mathrm{mL^{-1 }}$ (b); As(III): $1.0 \mathrm{ng} \mathrm{mL}^{-1}$ (d); vaporization temperature: $2000{ }^{\circ} \mathrm{C}$. 
1.0-7.0. As shown in Figure 2, the maximal signal intensity of As(III) was obtained in the $\mathrm{pH}$ range of 2.0-6.5, whereas the signal intensity of As(V) was hardly detected in the $\mathrm{pH}$ range of 4.5-6.5. The reason for this is that As(III) can react with APDC to form 1-dodecanol extractable As(III)-APDC complexes, but As(V) does not form APDC complexes extracted by 1-dodecanol. Based on the results mentioned above, a $\mathrm{pH}$ of 5.5 was used for separation of the different species of inorganic As. It should be pointed out that the investigation on its organic forms with this method will be carried out in future work.

\section{Quantitative Vaporization of Analytes}

In this work, quantitative vaporization of the analytes As(III) and As(V) was investigated with the addition of APDC at $\mathrm{pH}$ 5.5. The

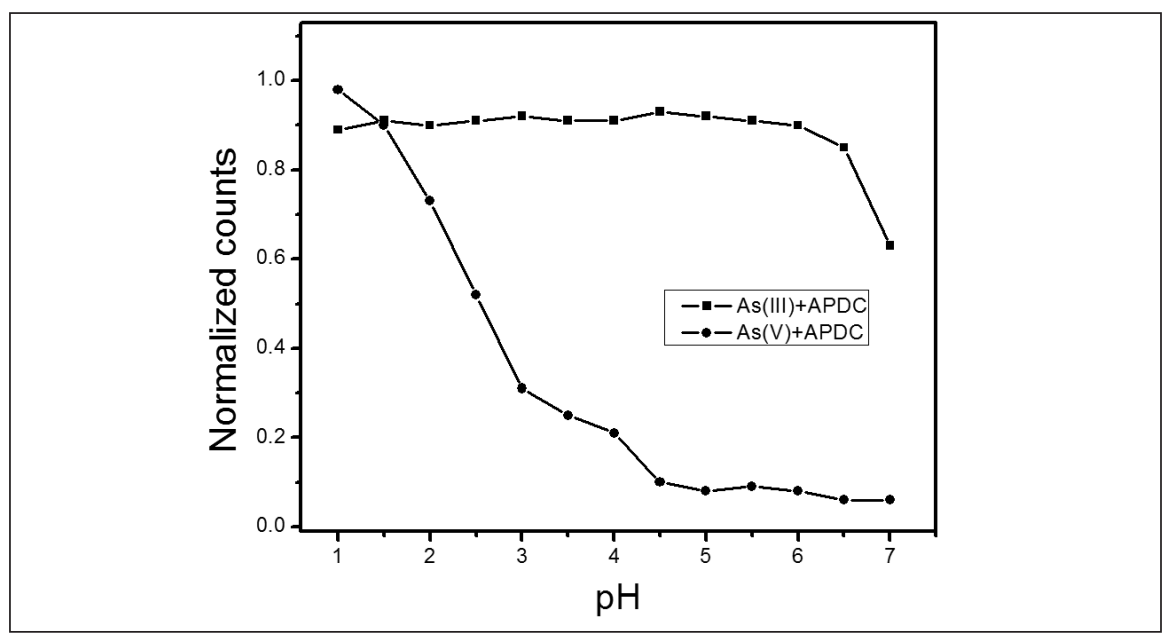

Fig. 2. Effect of pH on signal intensity. As(III) and As(V): $1.0 \mathrm{ng} m \mathrm{~L}^{-1}$; vaporization temperature: $2000{ }^{\circ} \mathrm{C}$. results in Figure 3 show that the signals for As(V) (f) can hardly be detected with APDC. In the presence of APDC, however, the intense and symmetrical signals for total As (g) were recorded due to the formation of the As(III)-APDC complex. It is worth noting that the signal intensity of total As (g) is about $50 \%$ of that for total As (h) after reduction by L-cysteine. The reason for this is that $\mathrm{As}(\mathrm{V})$ was reduced to As(III) to result in an increase of the concentration. In addition, a blank signal was not observed in the experiment (i). These facts indicate that the analytes can be quantitatively vaporized and transported from the ETV to the ICP under the selected conditions.

\section{Effect of APDC Concentration}

The effect of APDC concentration on the signal intensity of the analytes was studied in the concentration range of $0.1 \times 10^{-2}$ to $4.0 \times 10^{-2} \mathrm{~mol} \mathrm{~L}^{-1}$. The results in Figure 4 indicate that the signal intensity of As(III) was increased with an increase in APDC concentration from $0.1 \times 10^{-2}$ to $1.0 \times 10^{-2} \mathrm{~mol} \mathrm{~L}^{-1}$,

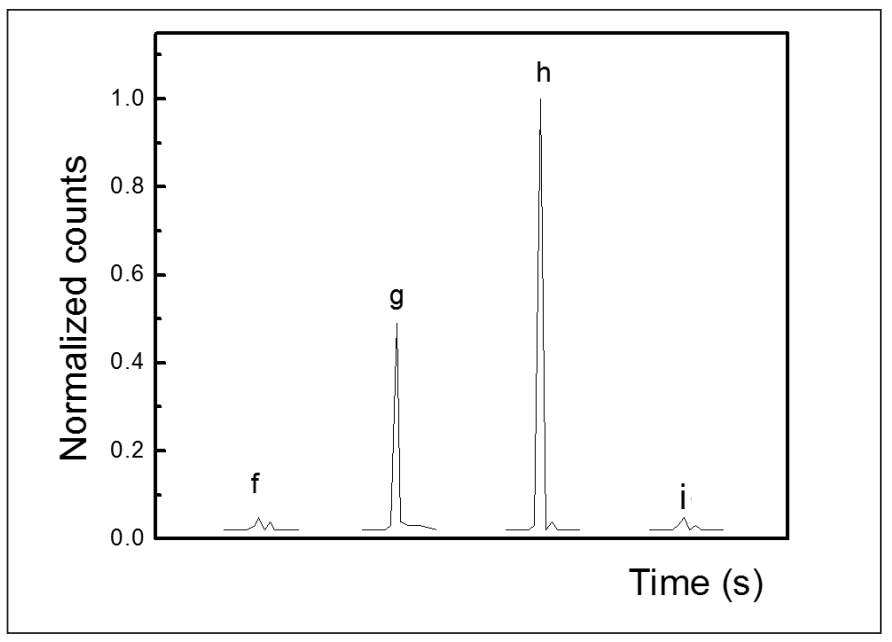

Fig. 3. Quantitative vaporization of analytes. $f: A s(V)$ with APDC in 1-undecanol and THF; g: total As with APDC in 1-undecanol and THF; b: total As with APDC in 1-undecanol and THF after reduction by L-cysteine; $i: A P D C+L$-cysteine in 1-undecanol and THF. Total As: As(III) + As(V);As(III) and As (V): $1.0 \mathrm{ng} \mathrm{mL}^{-1}$; vaporization temperature: $2000^{\circ} \mathrm{C}$.

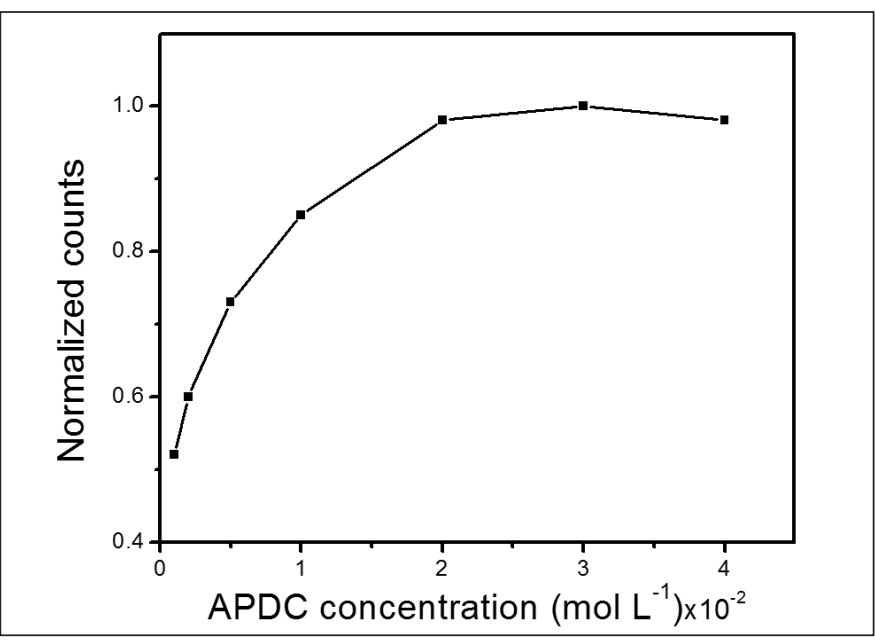

Fig. 4. Effect of APDC concentration on SFODME. As(III): $1.0 \mathrm{ng} \mathrm{mL}^{-1}$; vaporization temperature: $2000{ }^{\circ} \mathrm{C}$. 
and then kept nearly constant when the concentration of APDC exceeded $2.0 \times 10^{-2} \mathrm{~mol} \mathrm{~L}^{-1}$. Thus, the concentration of $3.0 \times 10^{-2}$ mol L ${ }^{-1}$ APDC was used for subsequent work.

\section{Influence of Extraction Time}

In order to achieve good precision, sensitivity. and speed, it is necessary to select an extraction time that guarantees the achievement of equilibrium between the aqueous and organic phases and maximizes extraction efficiency. For this reason, the effect of extraction time on the signal intensity of As(III) was investigated by varying the extraction time from 10 and 60 minutes. The experimental results show that the signal intensity of As(III) increased with extraction time, and then reached a plateau after 30 minutes. Thus, an extraction time of 30 minutes was used in this work.

\section{Influence of Stirring Rate}

Agitation of the sample solution is another factor that plays an important role in enhancing the extraction efficiency and reducing the extraction time. In order to accelerate mass-transfer of analytes from the aqueous to the organic phase, the sample solution of $20 \mathrm{~mL}$ was continuously agitated at different stirring rates from 100 to 1200 $\mathrm{rpm}$. The experimental results show that the signal intensities of the analytes increased rapidly with an increase in the stirring rate up to $900 \mathrm{rpm}$. However, the signal intensity decreased obviously when the stirring rate exceeded $1000 \mathrm{rpm}$ owing to the loss of floating solvent. Hence, a stirring rate of $900 \mathrm{rpm}$ was employed for analysis.

\section{Effect of Sample Volume}

The sample volume may influence the extraction efficiency of the analytes in a given time. In addition, an increase in volume ratio of the aqueous phase to organic phase can result in a significant increase of the enrichment factor. In order to study the effect of sample volume on the extraction efficiency, some experiments were carried out using different sample volumes $(5.0-40 \mathrm{~mL})$. The obtained results indicate that the extraction was quantitative (recovery $>90 \%$ ) with an aqueous phase volume ranging from 10-20 mL. However, a decrease was observed with a further increase in sample volume. Based on the organic phase volume $(20 \mu \mathrm{L})$ and the maximum sample volume $(20 \mathrm{~mL})$, an enrichment factor of 1000 was obtained for the analytes. Considering the two factors of analysis time and enrichment factor, the sample volume of $10 \mathrm{~mL}$ was used for further experiments.

\section{Effect of Interfering Ions}

In order to evaluate the application potential of this method, the effect of various cations and anions commonly existing in natural water on the extraction and determination of the analytes was examined. The tolerance limit of coexisting ions is defined as the largest amount making variations of less than $10 \%$ in the recovery of the analytes. The experimental results in Table II show that the selected ions were not found to interfere with the determination of As(III) and $A s(V)$ in the range of their concentration.

\section{TABLE II}

\section{Effect of Interfering Ions}

\begin{tabular}{lc}
\hline $\begin{array}{l}\text { Diverse } \\
\text { Ions }\end{array}$ & $\begin{array}{c}\text { Concentration } \\
\text { Ratio }\end{array}$ \\
\hline $\mathrm{Na}^{+}, \mathrm{K}^{+}$ & 20,000 \\
$\mathrm{Ca}^{2+}, \mathrm{Mg}^{2+}$ & 10,000 \\
$\mathrm{Fe}^{3+}, \mathrm{Zn}^{2+}, \mathrm{Al}^{3+}$ & 500 \\
$\mathrm{SO}_{4}{ }^{2-}, \mathrm{SiO}_{3}{ }^{2-}, \mathrm{PO}_{4}{ }^{3-}$ & 10,000 \\
$\mathrm{Cl}^{-}, \mathrm{NO}_{3}{ }^{-}$ & 20,000 \\
\hline
\end{tabular}

${ }^{a}$ Foreign ion / analyte.

\section{Optimization of ETV Conditions}

In this work, a drying temperature of $100^{\circ} \mathrm{C}$ and a drying time of 10 seconds were used for removal of the water vapor. To remove the extraction solvent from the furnace as much as possible and to avoid signal loss of the analytes at the same time, the effect of pyrolysis temperature on signal intensity was studied in the range of $100-400{ }^{\circ} \mathrm{C}$ with a pyrolysis time fixed at 20 seconds. The experimental results show that the signal intensity of As(III) decreased obviously with an increase in pyrolysis temperature above $250{ }^{\circ} \mathrm{C}$ due to the thermal decomposition of their complexes. Based on the above facts, a pyrolysis temperature of $200{ }^{\circ} \mathrm{C}$ and a pyrolysis time of 20 seconds were selected for the following experiments.

Under the selected drying and pyrolysis conditions, the effect of vaporization temperature on the signal intensity of the analytes was studied with a vaporization time of 4 seconds. The experimental results show that the signal intensity of the analytes could only be detected at about $800{ }^{\circ} \mathrm{C}$ without APDC, and no signal plateau was obtained in the vaporization temperature range tested. However, the situation changed greatly after APDC was added. A weak signal for As(III) appeared at $600{ }^{\circ} \mathrm{C}$ and the signal increased gradually with the increase in vaporization temperature. Maximum signal was obtained at $1800{ }^{\circ} \mathrm{C}$ for As(III), which was then kept constant with the further increase of vaporization temperature to $2200{ }^{\circ} \mathrm{C}$. Therefore, a vaporization temperature of $2000{ }^{\circ} \mathrm{C}$ and a vaporization time of 4 seconds were used in this work.

\section{Analytical Performance}

Under the optimized conditions, the linear dynamic range of the calibration curve for this method covered three orders of magnitude with a correlation coefficient better 
than 0.9951 . The detection limits of As(III) and As(V), based on three times the standard deviation of the blank solution, were $0.36 \mathrm{pg} \mathrm{mL}^{-1}$ and $0.91 \mathrm{pg} \mathrm{mL}^{-1}$, respectively. The relative standard deviations were 5.1\% and 5.7\% for As(III) and As(V) $\left(\mathrm{n}=9, \mathrm{c}=0.1 \mathrm{ng} \mathrm{mL} \mathrm{L}^{-1}\right)$, respectively.

\section{Sample Analysis}

This method was used for the determination of As(III) and As(V) in natural water samples, including lake water and river water. In addition, the recovery experiments of different amounts of analytes were carried out, and the results are summarized in Table III. It can be seen in this table that the recoveries are in the range of $93.0-105 \%$. In order to establish the validity of this method, a water certified reference material GSBZ50004-88, obtained from the Institute for Reference Materials of SEPA (Beijing, P.R. China), was analyzed, and the results were in good agreement with the certified values (Table IV).

\section{CONCLUSION}

In this paper, a novel method has been developed for the speciation of inorganic As by solidified floating organic drop microextraction (SFODME), coupled with electrothermal vaporization-inductively coupled plasma mass spectrometry (ETV-ICP-MS), using APDC and 1-undecanol as a chelating reagent and an extraction solvent in SFODME, respectively. At the same time, APDC acted as a chemical modifier in ETV-ICP-MS. The experimental results show that under the selected experimental conditions, the As(III)-APDC complex can be extracted effectively with 1 -dodecanol and vaporized quantitatively by ETV into the ICP for determination. In addition, this method provides advantages such as high enrichment factor, low detection limit, simple operation, low cost, good precision and accuracy. It has great potential to be used for

TABLE III

Analytical Results and Recoveries of Analytes in Natural Water Samples

\begin{tabular}{lccccc}
\hline Sample & Species & $\begin{array}{c}\text { Content } \\
\left(\mathrm{ng} \mathrm{mL}^{-1}\right)\end{array}$ & $\begin{array}{c}\text { Added } \\
\left(\mathrm{ng} \mathrm{mL}^{-1}\right)\end{array}$ & $\begin{array}{c}\text { Found } \\
\left(\mathrm{ng} \mathrm{mL}^{-1}\right)\end{array}$ & $\begin{array}{c}\text { Recovery } \\
(\%)\end{array}$ \\
\hline Lake Water & As(III) & $1.57 \pm 0.12$ & 1.0 & $2.52 \pm 0.14$ & 95.0 \\
& As(V) & $2.56 \pm 0.15$ & 1.0 & $3.61 \pm 0.23$ & 105 \\
River Water & As(III) & $0.19 \pm 0.02$ & 1.0 & $1.12 \pm 0.11$ & 93.0 \\
& As(V) & $1.98 \pm 0.17$ & 1.0 & $3.01 \pm 0.20$ & 103 \\
\hline
\end{tabular}

Mean value \pm standard deviation, $n=3$.

TABLE IV

Analytical Results of Analytes in Certified Reference Material of Water Sample

\begin{tabular}{llll}
\hline Sample & Element & Found $^{\mathrm{a}}\left(\mu \mathrm{g} \mathrm{\textrm {mL } ^ { - 1 } )}\right.$ & Certified $\left(\mu \mathrm{g} \mathrm{mL}^{-1}\right)$ \\
\hline $\begin{array}{llll}\text { GSBZ50004-88 } \\
\text { Water Sample }\end{array}$ & Total As & $0.0513 \pm 0.0038$ & $0.0479 \pm 0.0025$ \\
& As(III) & $0.0042 \pm 0.0003$ & - \\
& As(V) & $0.0471 \pm 0.0038$ & - \\
\hline
\end{tabular}

${ }^{\text {a }}$ Mean value \pm standard deviation, $n=3$.

speciation of inorganic As in environmental samples.

\section{ACKNOWLEDGMENT}

Financial support from the Nature Science Foundation and the Education Department Foundation of Hubei Province in China is gratefully acknowledged.

Received July 1, 2015.

\section{REFERENCES}

1. D.Q. Hung, O. Nekrassova, and R.G. Compton, Talanta 64, 269 (2004).

2. Y. Hu, X. Hu, H. Liu, L. Huang, and R. Liu, At. Spectrosc. 35(2), 90 (2014).

3. J. Lewis, P. Stokes, N. Brereton, M. Baxter, and R. Macarthur, Microchem. J. 105, 56 (2012).

4. P. Belanger and P. Dumas, At. Spectrosc. 31(6), 175 (2010).

5. Z. Li, C. Shizhong, L. Dengbo, and C. Xiuli, At. Spectrosc. 30(6), 218 (2009).
6. J.C. Ng, Environ. Chem. 2, 146 (2005).

7. J. Koh, Y. Kwon, and Y. Pak, Microchem. J. 80(2), 195 (2005).

8. E.R. Ricardo, L. Ignacio, and H. Manuel, Spectrochim. Acta Part B 64, 329 (2009).

9. C.K. Jain and I. Ali, Water Res. 34(17), 4304 (2000).

10. M.A. Vieira, P. Grinberg, C.R.R. Bobeda, M.N.M. Reyes, and R.C. Campos, Spectrochim. Acta Part B 64, 459 (2009).

11. M. Soylak and N. Kizil, At. Spectrosc. 34(6), 216 (2013).

12. L. Zhang, X. Li, X. Wang, W. Wang, $\mathrm{X}$. Wang, and H. Han, Anal. Meth. 6(15), 5578 (2014).

13. S. Mei, L. Guijian, and W. Qianghua, Food Chem. 141(1), 66 (2013).

14. X. Yang, W. Zhang, T. Chen, and X. Chu, At. Spectrosc. 31(1), 1 (2010).

15. S. Chen, S. Zhu, Y. He, and D. Lu, Food Chem. 150, 254 (2014).

16. P. Mamatha, G. Venkateswarlu, A.V.N. Swamy, and A.C. Sahayam, 


\section{A tomic \\ 1 Vol. 36(6), Nov./Dec. 2015}

Anal. Meth. 6(24), 9653 (2014).

17. B. Chen, W.T. Corns, P.B. Stockwell, and J.H. Huang, Anal. Meth. 6(18), 7554 (2014).

18. Y. Li, G. Hou, Z. Zhang, and Y. Zhao, At. Spectrosc. 32(4), 160 (2011).

19. M. Ghambarian, Y. Yamini, and A. Esrafili, Mirochim. Acta 180(7-8), 519 (2013).

20. Z. Xu, C. Liu, H. Zhang, Y. Ma, and S. Lin, Anal. Sci. 19(12), 1625 (2003).

21. A. Maite, R. Martín, and V. Frank, Anal. Chim. Acta 648(1), 23 (2009).

22. H. Sun, L. Zhao, B. Yang, and Q. Liu, At. Spectrosc. 35(6), 265 (2014).

23. C. Yuan, J. Wang, and Y. Jin, Mirochim. Acta 177, 153 (2012).

25. S. Mojtaba, F. Nazir, A. Yaghoub, S. Marzieh, and S. Kiomars, Talanta 130, 26 (2014).

26. Q. Liu, Y. Dong, J. Ma, and J. Li, Asian J. Chem. 26(15), 4921 (2014).

27. H. Sun, L. Zhao, B. Yang, and Q. Liu, At. Spectrosc. 35(6), 265 (2014).

28. S. Chen, X. Cheng, Y. He, S. Zhu, and D. Lu, Mirochim. Acta 180, 1479 (2013)

29. X. Guo, M. He, B. Chen, and B. Hu, Talanta 94, 70 (2012).

30. S. Chen, S. Zhu, and B. Lu, At. Spectrosc. 35(1), 1 (2014).

31. M.R.K. Zanjani, Y. Yamini, S. Shariati, and J.A. Jonsson, Anal. Chim. Acta 585(2), 286 (2007).

32. 41 Y. Feng, H. Narasaki, L. Tian, and H. Chen, At. Spectrosc. 21(1), 30 (2000). 